\title{
Formação, sucessão e migração: trajetórias de duas gerações de agricultores do Alto Jequitinhonha, Minas Gerais
}

\author{
Kenia Fabiana Cota Mendonça* \\ Eduardo Magalhães Ribeiro* \\ Flávia Maria Galizoni ${ }^{\star \star \star}$ \\ Hélder Anjos Augusto ${ }^{* * *}$
}

\begin{abstract}
A agricultura familiar é um segmento fundamental para o abastecimento alimentar, a geração de ocupações e a conservação das culturas próprias do rural brasileiro. De acordo com vários autores, a continuidade desse segmento de agricultores tem sido ameaçada pela grande emigração de jovens em decorrência de transformações ocorridas no urbano e no rural. Este artigo analisa tal situação em dois municípios do Alto Jequitinhonha, Minas Gerais - região fortemente marcada pela presença da agricultura familiar -, investigando as trajetórias emigratórias de duas gerações de agricultores. Os resultados indicam mudanças no padrão sucessório, nos níveis de escolaridade e na dinâmica tradicional de capacitação de jovens, o que influi nos percursos e na inserção dos migrantes no mercado de trabalho. 0 artigo conclui que, comparativamente à geração anterior, um menor número de jovens permanece no rural. Mas isto não coloca em risco a reprodução da unidade familiar, pois continuam a existir sucessores, embora estes tendam a assumir a unidade produtiva com mais idade e escolaridade do que a geração anterior.
\end{abstract}

Palavras-chave: Agricultura familiar. Sucessão. Juventude rural. Vale do Jequitinhonha.

\footnotetext{
* Departamento de Ciências Contábeis da Univesidade Federal dos Vales do Jequitinhonha e Mucuri, Teófilo Otoni-MG, Brasil (kenia.mendonca@ufvjm.edu.br).

** Instituto de Ciências Agrárias da Universidade Federal de Minas Gerais - UFMG, Belo Horizonte-MG, Brasil (eduardomr@ pq.cnpq.br).

${ }^{* \star \star}$ Instituto de Ciências Agrárias da Universidade Federal de Minas Gerais - UFMG, Belo Horizonte-MG, Brasil (flaviagalizoni@ yahoo.com.br).

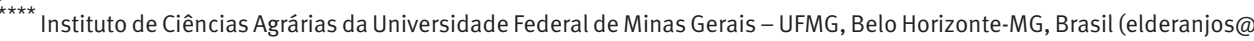
yahoo.com.br).
} 


\section{Juventude rural}

Nas unidades familiares de produção da região do Alto Jequitinhonha, Minas Gerais, denominadas sítios, os lavradores produzem frutas, hortaliças e grãos, beneficiam cana, milho e mandioca para produzir rapadura, fubá, canjica, farinha e polvilho - ou goma, a denominação local -, criam grandes e pequenos animais e se abastecem de carne, leite e ovos. Além disso, eles vendem essa produção familiar nas feiras livres, abastecendo, dessa forma, a população da cidade e do campo.

Esses agricultores familiares respondem por parte relevante da produção de alimentos e matérias-primas no Brasil. Segundo o Censo Agropecuário de 2006, eles dirigem 85\% dos estabelecimentos rurais, exploram 30\% da área agrícola e respondem por 38\% da produção e 66\% da ocupação na agropecuária. Apesar disso e do apoio de programas públicos, desde a década de 1990, observa-se que filhos e filhas de agricultores - sucessores da unidade familiar - têm buscado oportunidades de trabalho fora do meio rural.

Os estudos sobre sucessão indicam que transição demográfica, diferenciais de educação, integração campo-cidade, renda baixa, masculinização e envelhecimento no campo estimulam as emigrações. Assim, como a qualificação do agricultor é associada ao trabalho familiar - é trabalhando que crianças e jovens se habilitam para ocupações rurais -, a reprodução dessa cultura material estaria ameaçada. Por isso são recomendados programas voltados para a juventude rural capazes de integrar os jovens ao meio que conhecem.

Este artigo aborda a situação em Turmalina e Veredinha, municípios da região do Alto Jequitinhonha, investigando se e em que condições os jovens permanecem no rural. O estudo enfoca herança e sucessão na agricultura familiar, os mecanismos formais e tradicionais de capacitação e analisa os efeitos das transformações do rural sobre a sucessão.

\section{A pesquisa}

Os dados qualitativos e quantitativos foram coletados em 2007, por meio de entrevistas focalizadas na família ampliada, investigando a história de formação, migração e sucessão vivida por 40 casais com idades entre 30 e 71 anos, que representavam 10\% dos agricultores familiares dos municípios de Turmalina e Veredinha, do Alto Jequitinhonha. As informações abrangeram três gerações vinculadas a uma mesma terra: marido, mulher e seus irmãos, para compreender o acesso à terra do sítio, a sucessão passada e o plano da futura sucessão; seus pais, para entender a lógica de acesso à terra e a presença de eventuais padrões sucessórios; e seus filhos, para identificar a sucessão em processo. Os casais pesquisados foram amostrados intencionalmente, seguindo indicações de organizações rurais, distribuídos entre as diversas áreas agrícolas dos municípios e obedecendo aos critérios de prática agrícola, moradia rural e descendência. ${ }^{1}$

\footnotetext{
${ }^{1}$ Sobre a dinâmica sucessória camponesa, ver Leach (1961), Wolf (1976), Moura (1978) e Woortmann e Woortmann (1997); sobre métodos de pesquisa social, ver Marconi e Lakatos (1996). Os entrevistados foram indicados pelo Centro de Agricultura Alternativa Vicente Nica e Sindicatos de Trabalhadores Rurais dos dois municípios.
} 
A amostra foi distribuída proporcionalmente ao número de estabelecimentos familiares existentes em 1996 no município de Turmalina - do qual Veredinha então era distrito -, com base nos dados sistematizados Incra/FAO (2000) sobre agricultura familiar dos municípios. Além disso, a amostra seguiu a proporcionalidade dos grupos definidos pelo Programa Nacional de Fortalecimento da Agricultura Familiar - Pronaf: grupo B, renda familiar anual bruta até R\$ 2 mil; grupo C, renda familiar anual bruta entre $R$ \$ 2 mil e $R \$ 14$ mil; e grupo $D$, renda familiar anual bruta entre $R \$ 14$ mil e R $\$ 40$ mil (ORTEGA, 2008). Foi feita correção na amostra do grupo $D$, em face de modificações apontadas pelas agências de crédito e extensão rural no perfil da distribuição entre 1996 e 2006. A Tabela 1 detalha a amostragem.

TABELA 1

Amostra dos casais de agricultores familiares entrevistados de acordo com os critérios do Pronaf e da base Sade/Incra/FAO

Município de Turmalina, MG - 2007

\begin{tabular}{|c|c|c|c|c|c|}
\hline \multirow{2}{*}{$\begin{array}{l}\text { Grupos } \\
\text { Pronaf }\end{array}$} & \multirow{2}{*}{ Classes de renda } & \multicolumn{2}{|c|}{ Estabelecimentos existentes } & \multicolumn{2}{|c|}{ Amostra pesquisada } \\
\hline & & N. abs. & $\%$ & N. abs. & $\%$ \\
\hline Grupo D & Maior renda & 39 & 9,7 & 6 & 15,0 \\
\hline Grupo C & Renda média & 146 & 36,5 & 14 & 35,0 \\
\hline \multirow[t]{2}{*}{ Grupo B } & Renda baixa & 118 & 29,5 & - & - \\
\hline & Quase sem renda & 97 & 24,3 & 20 & 50,0 \\
\hline Total & & 400 & 100,0 & 40 & 100,0 \\
\hline
\end{tabular}

Fonte: Incra/FAO (2000) e Ortega (2008).

Além dos casais, foram entrevistados 40 filhos(as) desses agricultores, com idades entre 12 e 25 anos, sendo 20 rapazes e 20 moças. Esses jovens foram amostrados pelos mesmos critérios usados para escolher os casais. Os entrevistados forneceram ainda informações sobre os 141 filhos(as) e os 282 irmãos(ãs) do homem e da mulher que formam o casal e os 115 irmãos(ãs) dos(as) 40 filhos(as) de agricultores pesquisados, conforme exposto no Quadro 1. Para facilitar a compreensão do texto, os grupos dos casais e de seus irmãos(ãs) serão denominados “adultos” e os demais serão denominados "jovens”.

QUADRO 1

Total dos indivíduos sobre os quais foram coletadas informações na pesquisa Municípios de Turmalina e Veredinha, MG - 2007

\begin{tabular}{|lll|}
\hline Categorias & Entrevistados(as) & Que informaram sobre \\
\hline Cônjuges (membros do casal) & 40 casais ou 80 indivíduos & 141 filhos(as) destes casais \\
& & 282 irmãos(ãs) destes casais \\
\hline Filhos & 40 moças e rapazes & 115 irmãos(ãs) destes jovens \\
\hline Total & 120 & $\mathbf{5 3 8}$ \\
\hline
\end{tabular}

Fonte: Pesquisa com agricultores do Alto Jequitinhonha, 2007.

\section{Migração, herança e sucessão}

Em estudo clássico sobre camponeses brasileiros, Moura (1978) observou que o Código Civil, que institui partilha igual da herança entre os filhos, era ignorado nessas sociedades 
para evitar a fragmentação excessiva da terra. O costume é o lavrador se habilitar a comprar a herança da sua irmã, o que geralmente é feito com recursos da venda da parcela herdada pela sua mulher, preferencialmente para o irmão desta. Mulheres herdam por intermédio do casamento e, como os terrenos herdados pelo casal raramente são contíguos, os acertos de terras e casamentos entre os grupos familiares estão associados à necessidade de reunir o patrimônio herdado pelo casal numa só gleba.

Essas vendas de "preferência” ou "consideração", às vezes priorizando um herdeiro e excluindo outros, são analisadas também por Seyferth (1985), Garcia Júnior (1991) e Woortmann (1994). As soluções encontradas para transmitir o patrimônio entre gerações variam por grupos rurais e regiões, mas definem padrões de herança que revelam adaptações feitas pelas famílias sempre com dois objetivos claros: conservar pelo menos um herdeiro na terra; e evitar a venda da terra para pessoas de fora do grupo familiar. Por isso os herdeiros preferem vender sua parte a outro(a) herdeiro(a). Quando não é possível, eles vendem em parcelas ou a preço reduzido a parentes, de modo a favorecer a transação.

No mesmo movimento da herança, mas não necessariamente ao mesmo tempo, costuma ser resolvida a sucessão, que constitui a assunção de uma nova geração de agricultores ao comando da unidade produtiva, concluída com a transferência do patrimônio, a saída da geração anterior da gestão do estabelecimento e a continuidade da família e da atividade na terra. No primeiro movimento há transmissão da terra e dos ativos para outra geração; no segundo, ocorre a passagem da gerência e da capacidade de utilização do patrimônio. Por fim, a sucessão se completa com a redução do trabalho e do mando de uma geração sobre os ativos da unidade de produção. O propósito da sucessão é fazer com que pelo menos um herdeiro reproduza a unidade familiar (MOURA, 1978; RIBEIRO, 1993; WOORTMANN, 1994; CASTRO, 2005).

Na história de uma família rural, o momento da sucessão - da mesma forma que o da herança - varia com a idade e a formação dos filhos, a idade dos pais, o desempenho da unidade produtiva e a economia local. A solução da herança e da sucessão vai se impondo aos sujeitos, à terra e aos destinos na passagem da infância para a idade adulta. ${ }^{2}$

Entretanto, estudos recentes têm revelado mudanças nessa dinâmica da sucessão. Woortmann (1994) já observava que filhos(as) de agricultores valorizavam cada vez menos o modo de vida rural, sendo que a posição de sucessor passava a representar um ônus para jovens que preferiam trabalhar em fábricas. Nisso a autora via sinais de substituição do coletivo da família pelo "indivíduo" e enfraquecimento dos vínculos com a unidade familiar. Carneiro (1998) constatou que, em função de escolhas individuais, deixara de vigorar a norma costumeira de tornar sucessor o filho mais novo nas áreas em que pesquisara. Camarano e Abramovay (1998) perceberam uma tendência acentuada de saída dos jovens do campo, transformando a sucessão num problema. Silvestro et al. (2001) observaram que as

\footnotetext{
2 Para uma definição de agricultura familiar, consultar Lamarche (1993); sobre herança, ver Moura (1978), Heredia (1979), Seyferth (1985), Garcia Júnior (1991), Woortmann (1994), Santana e Costa (2004) e Galizoni (2007); sobre sucessão, consultar Abramovay (1998), Silvestro et al. (2001), Mello et al. (2003a), Castro (2005) e Sacco dos Anjos e Caldas (2006).
} 
oportunidades para jovens agricultores eram melhores fora do rural e que havia um aumento do número de unidades sem sucessores. Mello et al. (2003a) identificaram a desaparição da unidade de destinos entre família e indivíduo, sendo que a condição de agricultor perdia caráter "moral”. Segundo esses autores, o desinteresse dos jovens limitava a perspectiva de reprodução das unidades familiares.

Silvestro et al. (2001) observaram a redução no tamanho das famílias rurais provocada, de acordo com Camarano e Abramovay (1998), pela queda da taxa de fecundidade total. O decréscimo no número de filhos diminuiu o número de herdeiros potenciais, ao mesmo tempo que ocorria elevação da escolaridade e da emigração de jovens rurais (CARNEIRO, 1998; MARTELETTO, 2002; SANTANA; COSTA, 2004). Essa emigração era mais intensa para mulheres jovens: em 1995, havia 5,2 milhões de homens a mais do que mulheres no rural latino-americano; diferença que atingia 1,8 milhão entre aqueles de 15 a 29 anos (CAMARANO; ABRAMOVAY, 1998). Estes autores sugerem que isso devia-se ao aumento de oportunidades para moças no setor serviços, ao incentivo à emigração e à valorização dos estudos pelas mulheres. Assim, acentuaram-se a masculinização e o envelhecimento, reduzindo a oportunidade de renovação da agricultura familiar, pois emigravam jovens já detentores de saber qualificado adquirido na escola e no campo (MELLO et al., 2003b).

O envelhecimento relativo da população rural é acentuado pela queda no número de jovens no campo, pela migração de retorno ao campo de aposentados urbanos e pelo aumento da expectativa de vida. Cresceu a expectativa de vida produtiva dos pais, ampliando o período de trabalho conjunto com os(as) filhos(as) e levando os jovens rurais a se ocuparem no urbano (MELLO et al., 2003a, 2003b; SACCO DOS ANJOS; CALDAS, 2005).

Posteriormente, na segunda metade da década de 1990, pesou nesse cenário o declínio dos ganhos da agricultura familiar, em função da elevação das escalas produtivas, da abertura às importações, da queda de preços e das barreiras à entrada de pequenos produtores nos mercados. Nos anos 2000 a mecanização agrícola reduziu os empregos rurais, sendo que o campo e a cidade se integraram pelos transportes e comunicações, aumentando o número de ocupados em atividades não agrícolas (GRAZIANO DA SILVA, 2002; SACCO DOS ANJOS; CALDAS, 2006; BALSADI, 2008).

Embora essas transformações desafiem a reprodução da agricultura familiar, é preciso considerá-las à luz das condições heterogêneas do campo brasileiro, dos agroecosistemas, das culturas materiais, dos estilos de integração e dos programas públicos. Tais características manifestam-se de diversas maneiras conforme as peculiaridades regionais. A educação formal tem peso diferente nos vários segmentos do mercado de trabalho; neles, a emigração definitiva de jovens, principalmente do sexo masculino, não se distingue facilmente de migrações sazonais de longa duração; o fortalecimento da posição dos idosos e mulheres nas famílias graças aos programas públicos - aposentadorias e Bolsa-Família - certamente influi de forma diversa nas escolhas feitas por jovens. ${ }^{3}$

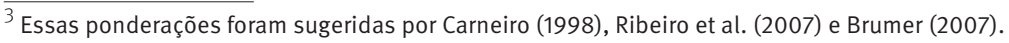




\section{Turmalina e Veredinha, Alto Jequitinhonha}

Desde a década de 1980, os pesquisadores perceberam a força das emigrações no Alto Jequitinhonha. Como a região é muito integrada ao mercado nacional de trabalho, os lavradores migram sazonal ou definitivamente para fronteiras agrícolas, trabalho urbano, corte de cana em São Paulo ou serviços diversos (MARTINS, 1986; RIOS NETO; VIEIRA, 1990; RIBEIRO, 1993). A pequena unidade familiar de produção é majoritária neste rural: há pouca integração com mercados agrícolas, sendo relevante a produção de autoconsumo. Dadas essas condições estruturais de reprodução e as tendências emigratórias recentes, as agências de desenvolvimento rural da região temem que esteja ocorrendo a dissolução da família rural, acelerada pela emigração de sucessores.

Na região estudada, a família rural pode ser nuclear - constituída por pai, mãe e filhos -, ou extensa, quando agrupa mais de uma família nuclear; quase sempre o que se constata é um meio termo entre essas duas formas. Família extensa é um resguardo para evitar a fragmentação excessiva da terra, que poderia inviabilizar a reprodução. Mas é a família que origina o trabalho, e este, tanto quanto família e terra, é essencial para a reprodução, sendo organizado em função do espaço e do tempo. O espaço do trabalho é a unidade familiar, o sítio, dividido entre casa, lavoura, pastos e chapadas (RIBEIRO; GALIZONI, 2000; GALIZONI, 2007).

O tempo do trabalho é dividido em duas épocas distintas. No verão, período em que chove de novembro a março, ocorrem plantios, tratos culturais e colheitas. De abril a outubro, quando há falta de chuvas, o trabalho agrícola é reduzido e as famílias se ocupam com artesanato e indústria doméstica, beneficiando cana-de-açúcar, mandioca e milho. Esses trabalhadores costumam definir como "livre" o tempo em que trabalham nas suas próprias unidades e, como "cativeiro", o trabalho para outros - em São Paulo ou recebendo por dia de serviço para vizinhos ou fazendeiros. ${ }^{4}$

Quando descrevem a divisão do trabalho usada nas unidades produtivas, os agricultores afirmam que cabem aos homens os serviços da roça e seu planejamento, o comércio e a transmissão do saber agrícola, ficando por conta das mulheres os serviços de casa, cuidados com filhos, preparo e beneficiamento de alimentos, cuidados de aves e animais. Apesar disso, todas as etapas do trabalho na lavoura costumam ser feitas pelo casal, filhas e filhos, com exceção da roçada, geralmente atividade masculina (AMARAL, 1988; GALIZONI, 2007).

As crianças participam do trabalho. Meninos com oito anos já recebem tarefas que dão início ao ciclo de aprendizado e os levam de meninos a rapazes e, posteriormente, a homens que assumem a coordenação dos trabalhos. Meninas, a partir de dez anos, assumem tarefas domésticas, cuidam de animais domésticos, aprendem costura e trabalham nas lavouras. ${ }^{5}$

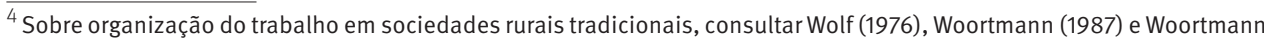
e Woortmann (1997); para o caso do Alto Jequitinhonha, consultar Amaral (1988), Ribeiro e Galizoni (2000), Noronha (2003) e Galizoni (2007).

${ }^{5}$ Sobre a divisão sexual de trabalho nas sociedades rurais, consultar Moura (1978), Heredia (1979) e Woortmann e Woortmann (1997); sobre o Alto Jequitinhonha, ver Noronha (2003) e Galizoni (2007).
} 
A emigração é frequente para os agricultores familiares de Turmalina e Veredinha desde a juventude, quando emigram definitiva ou sazonalmente para formar o patrimônio necessário ao casamento, ou, depois de casados, para garantir o sustento da família que se forma. A emigração definitiva revela que parte desses agricultores não pode permanecer na terra, migrando para reconstruir unidades produtivas em outros locais, sendo que, até conseguirem se restabelecer, a família extensa oferece a segurança das redes de solidariedade e apoio para aqueles que emigraram. Ao mesmo tempo essas pessoas dilatam laços pelo espaço e se reagrupam pelo parentesco, formando redes sociais que dão suporte aos fluxos migratórios (MARTINS, 1986; AMARAL, 1988; RIOS NETO; VIEIRA, 1990; RIBEIRO; GALIZONI, 2000; NORONHA, 2003).

A descendência define o acesso à terra nesses municípios onde predomina o regime agrário denominado de "terra no bolo": as glebas são indivisas e combinam uso e domínio privado e comunitário. Este regime garante a cada família o mínimo necessário em terra e recursos naturais para a exploração. Dessa forma, o sujeito do "acesso à terra não é um indivíduo, mas sim uma família, entendendo neste termo um grupo de parentesco em que as famílias nucleares são uma de suas faces" (GALIZONI, 2007, p. 44). ${ }^{6}$

A definição do sucessor resulta de um conjunto de passos. Primeiro ocorre a formação agrícola que capacita o jovem nos fundamentos da cultura material. Em seguida, tem-se a herança, que, sendo seletiva para reduzir a pressão sobre as poucas áreas de cultivo, abrange um ou poucos filhos. Neste passo, a filha é orientada preferencialmente para o casamento e, embora em certos casos possa assumir o domínio da terra, quase sempre seu acesso à terra dependerá das trocas de terras feitas entre seu marido e seus irmãos. Terceiro, a migração sazonal e a definitiva definem os destinos de parte dos herdeiros e dos sucessores. Por fim, a manutenção de recursos em comum - campos, florestas, aguadas e jazidas - potencializa os sistemas de produção e coloca a família numa relação de afinidade e tensão com a comunidade de parentesco, posta assim no centro da vida produtiva. Mas é preciso esclarecer que nem todas as famílias seguem estes passos, que resultam, sobretudo, de uma tipificação moral descrita por camponeses (RIBEIRO; GALIZONI, 2000).

Ao longo das décadas, a formação de novas famílias e a exploração contínua dos recursos na região resultaram em fragmentação da terra em Turmalina e Veredinha. O módulo fiscal, área definida como mínima para reprodução de uma família rural, corresponde a 40 hectares, mas a área média das unidades familiares nestes municípios atinge apenas 13 hectares (SADE/ FAO/INCRA, 2000). Essa subdivisão excessiva da terra muitas vezes inviabiliza a reprodução, estimula a emigração e problematiza a sucessão (NORONHA, 2003; GALIZONI, 2007).

\footnotetext{
${ }^{6}$ Sobre herança e domínio comum, consultar também Woortmann e Woortmann (1997), Ribeiro e Galizoni (2000) e Noronha (2003).
} 


\section{Os adultos}

Na porção adulta desta população, os 40 casais pesquisados apresentavam pequena variação na idade média (49 anos para homens e 47 anos para mulheres) e o número de filhos variava entre 4,5, no grupo de menor renda, e 3,5, naquele de maior renda. Os homens adultos tinham, em média, três anos de escolaridade e as mulheres 4,3 anos, e creditavam o curto período na escola a dois fatores: começaram a trabalhar ainda muito jovens e o acesso à escola na época era difícil. As escolas eram poucas ou não existiam, possuíam instalações precárias, faltavam professores qualificados, a frequência era incerta e a falta de transporte limitava o acesso e contribuía para a evasão.

Mas a educação formal influiu pouco na ocupação desses(as) lavradores(as). Foram os conhecimentos tradicionais da agricultura que deram a base para sua permanência no campo, pois começaram ainda crianças a aprender a trabalhar na terra da família, acompanhando os pais e passando depois às pequenas tarefas. Ao se tornarem adultos, o trabalho intensificouse até que aprenderam todas as atividades rurais. O saber foi apreendido pelo trabalho: os pais explicavam o serviço, os(as) filhos(as) experimentavam, os pais supervisionavam, corrigiam, e de novo explicavam. Assim dominaram as técnicas produtivas e a gerência da unidade de produção. Por isso, quando perguntados com quem aprenderam a trabalhar, $82,5 \%$ responderam que foi com o pai, que levava as crianças para a roça e ia ensinando. Apenas para $17,5 \%$ desses agricultores, que correspondem aos casos de pais falecidos que deixaram filhos(as) pequenos(as), foram a mãe e/ou o irmão mais velho que cuidaram da formação. Mas afirmar que o pai responde pelos ensinamentos não exclui outros membros da família dessa responsabilidade, pois eles trabalhavam partilhando conhecimentos e trocando experiências entre os membros da unidade produtiva.

Porém, a transmissão de conhecimento e a socialização do saber também envolvem relações com vizinhos e a comunidade, abarcando segmentos formais - associações, sindicatos, agências de extensão - e informais, como grupos religiosos e companheiros de migração. Para esses camponeses, a migração também é um momento de aprendizado, quando aprendem novas técnicas, novos produtos e conhecem cultivos que até então não usavam. Migrar possibilita ainda conviver com outras pessoas, conhecer a vida fora da localidade, ampliar o círculo de conhecidos e dominar novos ofícios - carpinteiro, pedreiro, cozinheiro, por exemplo. Já as mulheres que migraram aprenderam principalmente ocupações domésticas, pois trabalharam em média dois anos em casas de famílias.

Entre os agricultores adultos entrevistados, 32\% das mulheres e $72 \%$ dos homens migraram pelo menos uma vez e por curto período. Seus destinos foram os Estados de São Paulo, Paraná e Goiás, ou outros municípios de Minas Gerais, principalmente João Pinheiro, Paracatu, Curvelo, Pompéu e Belo Horizonte. Migrar temporariamente para cada um desses lugares, porém, foi decidido a partir das circunstâncias de época, da idade do migrante e da sua localidade de origem.?

\footnotetext{
${ }_{7}^{7}$ Sobre os destinos de migrantes do Alto Jequitinhonha, consultar Amaral (1988), Ribeiro (1993) e Ribeiro et al. (2003).
} 
Variam as idades em que esses agricultores migraram: $63 \%$ deles começaram ainda na adolescência, 22\% depois de casados; contudo, 68\% migraram quando solteiros e os 25\% que o fizeram depois de casados migraram no máximo três vezes. Há forte relação entre classes de renda e migração, comprovando a necessidade de buscar recursos para adquirir rebanho, equipamentos e terras.

Cada lavrador desenvolve estratégia própria para adquirir e/ou melhorar sua unidade produtiva. Entretanto, suas histórias têm aspectos em comum: formam patrimônio pelo trabalho, economizam recursos para criar excedentes e buscam maximizar esses excedentes. Fazendo economia, eles geram poupanças que guardam em casa, em bancos ou investem, principalmente em criações como gado, porco ou galinha, porque consideram importante, como dizem, "fazer o recurso girar". Gado é considerado o melhor investimento: "Não existe outra criação, caso você queira comprar terra, a não ser o gado” (Senhor V.). Porém, segundo seus relatos, gado dá despesa e ocupa tempo, pois é necessário plantar capim, fazer silagem, alimentar o animal e, às vezes, comprar ração.

Os adultos tornaram-se agricultores por circunstâncias distintas: 52,5\% foram indicados sucessores por seus pais e 47,5\% construíram a condição de agricultores em sítios diferentes, no próprio município. Os motivos para serem escolhidos sucessores dependeram de fatos como ser único filho homem, ter sido o único a permanecer no domicílio, por ter construído o direito à terra por meio do trabalho, ou pelo destino diverso dos irmãos, que emigraram em definitivo e encontraram trabalho e casamento em outro lugar.

Entre os adultos entrevistados que se tornaram sucessores(as) dos pais - herdaram casa e unidade de produção para continuarem nas mesmas atividades -, 90\% residiam e trabalhavam na mesma unidade que seus pais herdaram de seus avós. Eles valorizam o fato de residir e trabalhar na unidade familiar, pois assim guardam o patrimônio e a memória da família e, além de herdarem a terra para manter sua família, receberam recursos como animais, engenhos de cana-de-açúcar e alambiques, equipamentos relacionados às atividades produtivas.

Dos $47,5 \%$ dos adultos que se tornaram agricultores em outros municípios, $26 \%$ se casaram com herdeiros(as) e $74 \%$ compraram terra.

As informações sobre os demais adultos - irmãos ou irmãs dos membros dos casais entrevistados - revelam que alguns saem e outros ficam na terra, conforme mostra a Tabela 2. A escolha dependeu de circunstâncias externas, como acesso a trabalhos urbanos, compra de terras no próprio município ou em outro município vizinho.

Os dados da Tabela 2 indicam que 52\% dos irmãos e irmãs dos membros dos casais entrevistados se ocupavam em atividades urbanas, trabalhando em empregos permanentes, dentro e fora do município de origem, principalmente no setor de serviços (doméstico, educação, segurança, comércio) e na indústria.

Observa-se que 35\% desses adultos (irmãos ou irmãs dos casais entrevistados) migraram definitivamente para outras regiões do país. Destes, a maior parte $(66,34 \%)$ dirigiu-se para municípios mineiros, sendo que 30,69\% foram para Belo Horizonte, 10,89\% para Capelinha e 7,92\% para Minas Novas. O Estado de São Paulo recebeu 26,73\% desses migrantes 
definitivos, dos quais $54 \%$ são mulheres, confirmando que elas, mais do que os homens, migram em definitivo (RIBEIRO; GALIZONI, 2000).

Observa-se ainda, na Tabela 2, que 44\% dos adultos (irmãos e irmãs) tornaram-se agricultores. Destes, 9\% eram solteiros(as) ou viúvos(as) e trabalhavam na terra com a família; $72 \%$ eram casados, moravam e trabalhavam em terrenos herdados por eles ou pelos cônjuges e 19\%, também casados, compraram a terra. Aqui não foi possível averiguar se as compras caracterizaram-se como vendas preferenciais ou guiadas pela consideração a membro da família, conforme indicou Moura (1978).

TABELA 2

Distribuição dos adultos, irmãos e irmãs dos membros dos casais entrevistados, por localidade de residência atual, segundo situação de ocupação Municípios de Turmalina e Veredinha, MG - 2007

\begin{tabular}{lccc}
\hline \multicolumn{1}{c}{ Ocupação } & $\begin{array}{c}\text { Municípios de } \\
\text { Turmalina e Veredinha }\end{array}$ & $\begin{array}{c}\text { Outros } \\
\text { municípios }\end{array}$ & Total \\
\hline Agricultores & 39,0 & 5,0 & 44,0 \\
Trabalho urbano & 22,0 & 30,0 & 52,0 \\
Migrantes sazonais & 4,0 & 0,0 & 4,0 \\
Total & 65,0 & 35,0 & 100,0 \\
\hline
\end{tabular}

Fonte: Pesquisa com agricultores do Alto Jequitinhonha, 2007.

De acordo com os dados da Tabela 3, não há grande diferença entre o tempo médio que esses adultos - sejam eles agricultores, migrantes ou sucessores - frequentaram escola. Não se percebe em Turmalina e Veredinha - ao contrário do que aponta a literatura para outras regiões do país - que tenham sido escolhidos sucessores aqueles que estudaram menos. Percebe-se que o precário acesso à educação formal foi dividido equitativamente entre os irmãos e irmãs dos casais entrevistados.

TABELA 3

Tempo médio de estudo dos adultos agricultores(as) entrevistados(as) e seus irmãos(ãs), segundo faixas de renda

Municípios de Turmalina e Veredinha, MG - 2007

\begin{tabular}{cccc}
\hline $\begin{array}{c}\text { Faixas de } \\
\text { renda }\end{array}$ & $\begin{array}{c}\text { Tempo de estudo dos(as) } \\
\text { agricultores(as) } \\
\text { não sucessores(as) } \\
\text { entrevistados(as) }\end{array}$ & $\begin{array}{c}\text { Tempo de estudo } \\
\text { dos(as) agricultores(as) } \\
\text { sucessores(as) } \\
\text { entrevistados(as) }\end{array}$ & $\begin{array}{c}\text { Tempo de estudo dos(as) } \\
\text { irmãos(ãs) dos(as) } \\
\text { entrevistados(as) }\end{array}$ \\
\hline Menor renda & 2,5 & 1,9 & 3,5 \\
Média renda & 2,5 & 3,1 & 3,6 \\
Maior renda & - & - & 4,4 \\
\hline
\end{tabular}

Fonte: Pesquisa com agricultores do Alto Jequitinhonha, 2007.

\section{Jovens}

Os jovens, da mesma forma que os adultos entrevistados, adquiriram com a família os conhecimentos sobre o trabalho. Entretanto 59\% deles também aprenderam agricultura com 
vizinhos das comunidades rurais e consideram que essa convivência, além de fortalecer laços de amizade, possibilitou melhor desempenho no trabalho. Os conhecimentos são transmitidos por meio do fazer-aprender, que começa aos dez anos de idade. Desses jovens, 90\% trabalhavam com a família na lavoura, no beneficiamento e na comercialização de produtos.

Eles participam das atividades das organizações que atuam no meio rural, tais como o Sindicato dos Trabalhadores Rurais (10\% dos jovens), o Centro de Agricultura Alternativa Vicente Nica (25\%), a Associação de Promoção ao Lavrador e Assistência ao Menor de Turmalina (20\%), a Empresa de Assistência Técnica e Extensão Rural do Estado de Minas Gerais (20\%) e as Associações Comunitárias (10\%). Os jovens avaliam que essas organizações contribuem para o seu aprendizado e a valorização da agricultura familiar, fornecendo insumos a baixo custo, cursos para aprimorar conhecimentos, palestras técnicas sobre máquinas e insumos agrícolas. Contudo, a família continua sendo a base de formação do(a) jovem rural, pois é principalmente a partir do aprendizado na família que se consideram habilitados para desempenhar as atividades agrícolas.

Contudo, o padrão de frequência escolar se alterou em relação à geração anterior, revelando os resultados dos investimentos em ensino e da valorização social da formação escolar. Jovens com até 15 anos já possuem mais do que o dobro do tempo de escola que seus pais frequentaram: em média 6,7 anos. Mulheres, nas duas gerações, frequentaram mais escola do que os homens, conforme o Gráfico 1.

\section{GRÁFICO 1} Média de anos de estudo de jovens e adultos (pais, tios, mães e tias), segundo níveis de renda
Municípios de Turmalina e Veredinha, MG - 2007

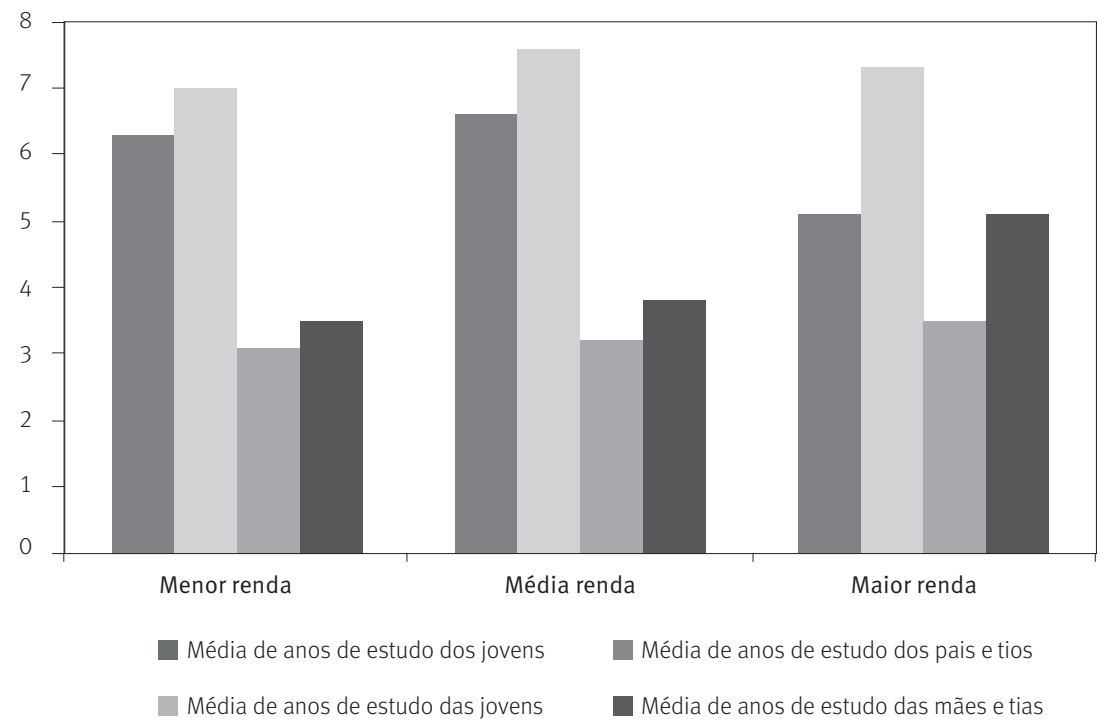

Fonte: Pesquisa com agricultores do Jequitinhonha, 2007. 
As escolas das comunidades rurais oferecem quatro anos de curso e, quando não há escola, as Prefeituras disponibilizam transporte escolar até as sedes urbanas. Dos(as) jovens rurais entrevistados(as), 95\% estudaram pelo menos dois anos na escola da comunidade, passando depois para escolas na sede do município ou para Escolas Família Agrícola. Estas últimas contribuem para aumentar a escolaridade ao adotarem o regime de alternância, no qual estudantes passam duas semanas na unidade familiar e outras duas na escola. A alternância estimula a articulação dos conhecimentos adquiridos na unidade de produção com aqueles ensinados na escola. Assim, os jovens estudam, contribuem para a produção agrícola familiar e recebem formação técnica útil para os que escolhem a vida rural.

A Tabela 4 apresenta informações sobre os(as) irmãos(ãs) dos(as) jovens pesquisados(as). Observa-se que 40,0\% deles estavam inseridos em atividades urbanas, principalmente no setor de serviços, dentro ou fora do município de origem, 21,0\% se ocupavam na agricultura familiar e 3,0\% haviam realizado migração sazonal, principalmente corte de cana-de-açúcar em São Paulo. Migrantes sazonais apresentavam, em média, 7,3 anos de estudo e 24 anos de idade, sendo que 64,0\% eram solteiros. Estudantes solteiros com idades entre 7 e 22 anos representavam $36,0 \%$ do total, dos quais $69,0 \%$ trabalhavam no campo com a família, 4,0\% estudavam em outros municípios mineiros e 27,0\% não se ocupavam na agricultura. Desses jovens, aqueles que não mais estudavam e migravam sazonalmente iam para os mesmos lugares que seus pais e tios(as): municípios dos Estados de São Paulo e Minas Gerais, com 47,3\% e 30,9\%, respectivamente.

TABELA 4

Distribuição de irmãos e irmãs de jovens entrevistados(as), por localidade de residência atual, segundo situação de ocupação

Municípios de Turmalina e Veredinha, MG - 2007

Em porcentagem

\begin{tabular}{lccc}
\hline \multicolumn{1}{c}{ Ocupação } & $\begin{array}{c}\text { Municípios de } \\
\text { Turmalina e Veredinha }\end{array}$ & $\begin{array}{c}\text { Outros } \\
\text { municípios }\end{array}$ & Total \\
\hline Estudantes & 34,0 & 2,0 & 36,0 \\
Trabalhadores urbanos & 23,0 & 17,0 & 40,0 \\
Agricultores & 19,0 & 2,0 & 21,0 \\
Migrantes sazonais & 3,0 & 0,0 & 3,0 \\
Total & $\mathbf{7 9 , 0}$ & $\mathbf{2 1 , 0}$ & $\mathbf{1 0 0 , 0}$ \\
\hline
\end{tabular}

Fonte: Pesquisa com agricultores do Jequitinhonha, 2007.

\section{Migração e sucessão}

Para comparar as trajetórias de "adultos" e "jovens”, ou seja, as trajetórias dos irmãos e irmãs dos jovens entrevistados com aquelas dos irmãos e irmãs dos casais entrevistados, foram excluídos os dados referentes aos(às) jovens que frequentam escola e que, portanto, ainda não definiram seus destinos (Tabela 5). Dessa forma, pode-se afirmar que:

- a proporção de agricultores passou de 44\% do total de filhos na primeira geração para $32 \%$ na segunda geração, indicando que existem menos $27 \%$ de agricultores familiares na geração jovem; 
- cresceu, entre as gerações, o percentual de filhos(as) de agricultores(as) ocupados em atividades urbanas, que passou de $52 \%$ para $62 \%$ do total.

TABELA 5

Proporção de adultos e jovens (exceto os que ainda frequentam escola) rurais, por localidade de residência atual, segundo situação de ocupação

Municípios de Turmalina e Veredinha, MG - 2007

Em porcentagem

\begin{tabular}{llccc}
\hline \multicolumn{2}{c}{ Ocupação } & $\begin{array}{c}\text { Municípios de } \\
\text { Turmalina e } \\
\text { Veredinha }\end{array}$ & Outros municípios & Total \\
\hline Agricultores & Adultos & 39,0 & 5,0 & 44,0 \\
Trabalhadores & Adultos & 29,0 & 3,0 & 32,0 \\
urbanos & Jovens & 22,0 & 30,0 & 52,0 \\
\multirow{2}{*}{$\begin{array}{l}\text { Migrantes } \\
\text { sazonais }\end{array}$} & Adultos & 36,0 & 26,0 & 62,0 \\
\hline
\end{tabular}

Fonte: Pesquisa com agricultores do Jequitinhonha, 2007.

Percebeu-se ainda que a média de anos de estudo não variou em função da ocupação desempenhada pelos(as) jovens: tanto aqueles ocupados na agricultura (6,3 anos de escolaridade para homens e 6,1 anos para mulheres) como os jovens inseridos em atividades urbanas (6,6 e 7,6 anos, respectivamente) frequentaram quase o mesmo tempo de escola. Assim, escolaridade não pode ser considerada fator determinante para definir quem permanece ou não no campo. Contudo, é preciso ponderar que nem todos esses jovens fizeram a escolha dos rumos que seguiram.

Mas sucessão pode ser relacionada também aos filhos e filhas dos 40 casais entrevistados. Segundo estes, sucessão se encontra em três situações distintas: há um vago horizonte de escolha do(a) sucessor(a); existem famílias que estão preparando sucessores(as); e há famílias sem sucessores(as), conforme mostra a Tabela 6.

TABELA 6

Casais rurais entrevistados, segundo situação da sucessão das terras Municípios de Turmalina e Veredinha, MG - 2007

\begin{tabular}{lcc}
\hline & Situação da sucessão & Casais \\
\hline Vago & Filhos(as) menores de dez anos & 5 \\
horizonte & Filhos(as) entre 10 e 17 anos & 3 \\
& Filhos(as) trabalhando em ocupações urbanas & 6 \\
Preparando & Sucessores(as) definidos(as) & 8 \\
sucessores(as) & Sucessores(as) não definidos(as) & 15 \\
Sem sucessores(as) & & 3 \\
Total & & $\mathbf{4 0}$ \\
\hline
\end{tabular}


Em 14 das 40 famílias existia apenas um vago horizonte de sucessão, das quais cinco possuíam filhos(as) menores de dez anos, o que dificulta depreender qual, ou quais se tornarão sucessores(as). Em três famílias, apesar de os(as) filhos(as) terem entre 10 e 17 anos, eles nunca trabalharam junto com os pais; como a transmissão do conhecimento pelo trabalho familiar é fundamental para a sucessão, estes jovens não estavam recebendo a capacitação necessária para se tornarem agricultores. As outras seis famílias são constituídas por filhas ou filhos já estabelecidos em ocupações urbanas, restando somente filhas na unidade produtiva familiar. Apenas em uma delas a filha foi explicitamente indicada como possível sucessora na unidade, e a jovem se mostra disposta a suceder aos pais no empreendimento.

Nas famílias que estão preparando seus sucessores, existem duas situações: aquelas que já definiram o sucessor (oito famílias); e aquelas que, dada a trajetória dos(as) filhos(as), ainda não o definiram (15). No primeiro caso, os sucessores, todos homens, já foram definidos e trabalham na unidade familiar. No segundo, observou-se uma média de 6,2 filhos(as) por casal, contra 3,1 no primeiro arranjo. Maior número de filhos(as) implica, certamente, mais opções para escolha de sucessores(as), criando também situação mais delicada para a escolha. Como todos os filhos e filhas são preparados para a sucessão e todos estão ainda decidindo seu futuro, além de os pais encontrarem-se em pleno vigor produtivo, não é possível saber qual(is) será(ão) os(as) sucessores(as). ${ }^{8}$

Por fim, na última situação, têm-se três famílias sem sucessores, sendo uma de agricultores de maior renda e duas de menor renda. No primeiro caso, a família é constituída por duas filhas que migraram em definitivo e cursam universidade. Nas duas famílias de menor renda sem sucessores, numa delas o casal de filhos já se estabeleceu em empregos urbanos e, na outra, a filha única era incentivada a estudar e procurar ocupação fora do rural. Neste caso a terra poderá voltar para o estoque da família extensa e a herança da terra pode se resolver saltando uma geração ou passando de tios para sobrinhos ou afilhados, conforme descrito por Galizoni (2007) para a região.

\section{Conclusões}

Os recursos para a capacitação de jovens para a agricultura continuam sendo os mesmos usados por seus pais: o conhecimento adquirido na família. Mas as redes comunitárias, a migração sazonal, as organizações formais e informais, governamentais e não governamentais também são importantes para a formação profissional e a inovação. Além disso, a escola passou a ocupar lugar destacado: os 6,9 anos médios de escola dos jovens representam quase o dobro da média dos 3,5 anos de escola dos adultos. Isso indica que os programas voltados para universalização da escola vêm atingido objetivos, com elevação do nível de escolaridade formal da população rural e valorização deste recurso.

\footnotetext{
$\overline{8}$ Família maior certamente implicará também patrimônio familiar maior - conforme indica Chayanov (1974) -, o que poderá permitir dotar alguns herdeiros e habilitar mais de um sucessor.
} 
Entre a população pesquisada nos municípios de Turmalina e Veredinha, não foram observadas diferenças em termos de anos de frequência à escola por sexo, renda ou destino, ao contrário do que a literatura registra em outras áreas rurais brasileiras. As jovens cursaram, em média, um ano a mais de escola do que os rapazes. A diferença do tempo de escola dos(as) jovens filhos(as) de agricultores com rendas maiores, médias e menores é inferior a um ano. Jovens com a mesma origem rural que exerciam atividades rurais ou urbanas possuíam na média o mesmo tempo de frequência à escola. Nos municípios pesquisados, o acesso à educação formal não estimula o abandono do meio rural. A educação é culturalmente considerada um dos meios para garantir "futuro" aos filhos e filhas diante das dificuldades do meio rural; mas não é o único meio nem torna moralmente obrigatória a saída do campo.

Os adultos valorizam culturalmente a escola para jovens, mas ponderam a necessidade de aliar educação formal com o saber técnico qualificado apreendido na vida no campo pelos(as) agricultores(as) e que é transmitido aos jovens. Para eles, iniciativas como as Escolas Família Agrícola são fundamentais para qualificar os jovens, pois integram as disciplinas com o cotidiano rural. Os adultos entrevistados consideram necessário que uma parte das escolas rurais ajuste seus programas à especificidade cultural, à sazonalidade e às demandas da população rural.

Tanto no caso dos adultos quanto dos jovens estudados, observou-se que a escolha de sucessores para as unidades familiares, pelo menos aparentemente, não obedece a critérios de sexo ou padrões de idade ou escolaridade. Filhos mais velhos, do meio ou mais moços, homens ou mulheres, com mais ou menos tempo de escola, se tornaram ou podem vir a ser sucessores. Mas observa-se que formar o sucessor é uma escolha, pois este recebe a responsabilidade de guardar a memória familiar junto com a terra. Diferentemente do que apontam os estudos feitos no Sul do país - como Mello et al. (2003a; 2003b), Sacco dos Anjos e Caldas (2005) e Silvestro et al. (2002), em que a sucessão é sentida como uma prisão pelo jovem e a ocupação agrícola perde seu caráter moral -, todos os jovens pesquisados manifestaram o desejo de permanecer na agricultura familiar e conservar os costumes da comunidade.

Contudo, a renda baixa na agropecuária pode interferir, e interfere, na permanência do jovem no campo. Diante disto, alguns pais até incentivam filhos(as) a buscarem oportunidades fora do rural.

Mas quando migram, sazonal ou definitivamente, os jovens o fazem com maior escolaridade do que os adultos que migraram. Apesar disso, eles costumam ir para as mesmas ocupações que aqueles foram. Neste aspecto não foi observada qualquer mudança relevante: os jovens continuam migrando na mesma proporção que os adultos.

Adultos responsáveis por estabelecimentos de menores rendas eram os que mais estimulavam jovens a procurarem ocupações urbanas, mesmo quando isso significava ausência de sucessor. Portanto, revela-se em Turmalina e Veredinha, assim como no Sul do Brasil, a necessidade de criar programas capazes de melhorar a renda agrícola, apoiando produção, beneficiamento e comercialização. 
Outro aspecto que interfere na permanência de jovens e na sucessão no campo é a longevidade dos pais, agindo em dois sentidos opostos. Por um lado, o aumento na expectativa de vida da população adulta rural dilata o prazo da sucessão e, por outro, as rendas advindas de aposentadorias e pensões oferecem mais segurança para investir, inovar e melhorar a produção.

Nas famílias entrevistadas percebeu-se o interesse de jovens em continuar nas atividades dos pais, mesmo que para isso tivessem que trabalhar simultaneamente em ocupações urbanas e na agricultura. Mas nota-se que, na área pesquisada, 15\% das famílias não registravam mais a presença de jovens residentes nas unidades familiares, percentual superior aos $12 \%$ observados no oeste de Santa Catarina por Silvestro et al. (2001). Entretanto, em somente $7,5 \%$ das famílias pesquisadas não existiam possíveis sucessores; este percentual é 4,5 vezes menor do que os 34\% encontrados no Rio Grande do Sul por Sacco dos Anjos e Caldas (2006).

Os dados da pesquisa em Turmalina e Veredinha mostraram, ainda, que a comparação entre a ocupação dos adultos - 44\% deles inseridos na agricultura - e a dos jovens integrados ao trabalho - 32\% já ocupados na unidade familiar - revela queda de $27 \%$ no número de filhos que permanecem no rural. Mas não é possível afirmar que essa redução de agricultores entre gerações deixe vazios os sítios: a área média das unidades familiares é tão pequena em função da fragmentação da terra nas últimas décadas que, mais do que parecer despovoá-las, a redução da permanência de jovens reordena seu uso, para garantilo em área suficiente para aqueles interessados em se ocupar no rural. Não é, certamente, o melhor dos métodos para redistribuir terra, porém, aqueles jovens que nesses municípios puderem optar por permanecer no rural vão fazê-lo em condições diferentes dos seus pais: aparentemente terão mais terra à disposição, concretamente receberão maior educação formal e, certamente, estarão um pouco mais envelhecidos.

\section{Referências}

AMARAL, L. Do Jequitinhonha aos canaviais. Dissertação (Mestrado). Fafich/UFMG, 1988.

ABRAMOVAY, R. (Coord.). Juventude e agricultura familiar: desafios dos novos padrões. Brasília, DF: Unesco, 1998. Disponível em: 〈http://www.econ.fea.usp.br〉. Acesso em: 11 abr. 2007.

BALSADI, O. V. 0 mercado de trabalho assalariado na agricultura brasileira. São Paulo: Hucitec, 2008.

BRUMER, A. A problemática dos jovens na pós-modernidade. In: CARNEIRO, M. J.; CASTRO, E. G. Juventude rural em perspectiva. Rio de Janeiro: MaudX, 2007.

CAMARANO, A. A.; ABRAMOVAY, R. Êxodo rural, envelhecimento e masculinização no Brasil: panorama dos últimos 50 anos. São Paulo: Ipea, 1998 (Texto para discussão, 621).

CARNEIRO, M. J. 0 ideal urbano: campo e cidade no imaginário de jovens rurais. 1998. Disponível em: 〈http://bibliotecavirtual.clacso.org.ar/ar/libros/anpocs/carne.rtf〉. Acesso em: 23 fev. 2007.

CASTRO, E. G. Entre ficar e sair: uma etnografia da construção social da categoria jovem rural. Tese (Doutorado). Rio de Janeiro, PPGAS/UFRJ, 2005. 
CHAYANOV, A. V. La organización de la unidad económica campesina. Buenos Aires: Nueva Visión, 1974.

GALIZONI, F. M. A terra construída. Fortaleza: Etene/BNB, 2007.

GARCIA JÚNIOR, A. R. 0 sul, caminho do roçado. São Paulo: Marco Zero, 1991.

GRAZIANO DA SILVA, J. F. 0 novo rural brasileiro. Campinas: IE/Unicamp, 2002.

HEREDIA, B. M. A. de. A morada da vida. Rio de Janeiro: Paz e Terra, 1979.

INCRA/FAO. Banco de dados da agricultura familiar: projeto de cooperação técnica Incra/FAO. Brasília, DF, 2000. Disponivel em: 〈http://www.incra.gov.br〉. Acesso em: 10 set. 2007.

LAMARCHE, H. A agricultura familiar. Campinas: Unicamp, 1993.

LEACH, E. R. Pul Eliya: a village in Ceylon. Cambridge: Cambridge University Press, 1961.

MARCONI, M. de A.; LAKATOS, E. M. Técnicas de pesquisa. 3. ed. São Paulo: Atlas, 1996.

MARTELETO, L. J. O papel da família na escolaridade dos jovens. Revista Brasileira de Estudos de População, v. 19, n. 2, jul./dez. 2002.

MARTINS, J. S. O vôo das andorinhas: migrações temporárias no Brasil. In: MARTINS, J. S. Não há terra para plantar neste verão. Petrópolis: Vozes, 1986.

MELLO, M. A. de; ABRAMOVAY, R.; SILVESTRO, M. L.; DORIGON, C.; FERRARI, D. L.; TESTA, V. M. Sucessão hereditária e reprodução social da agricultura familiar. Agricultura de São Paulo, v. 50, n. 1, p. 11-24, 2003a.

MELLO, M. A. de; SILVESTRO, M. L.; ABRAMOVAY, R.; DORIGON, C.; FERRARI, D. L.; TESTA, V. M. Educação formal e os desafios para a formação de uma nova geração de agricultores. In: CONGRESSO DA SOBER, 41, 2003, Juiz de Fora. Anais... Juiz de Fora: UFJF, 2003b, p. 1-14. Disponível em: 〈http://www.econ.fea. usp.br/abramovay/artigos_cientificos.pdf〉. Acesso em: 11 abr. 2007.

MOURA, M. M. Os herdeiros da terra: parentesco e herança. São Paulo: Hucitec, 1978.

NORONHA, A. G. B. 0 tempo de ser, fazer e viver: modo de vida de populações rurais tradicionais do Alto Jequitinhonha. Dissertação (Mestrado). Lavras, Universidade Federal de Lavras, 2003.

ORTEGA, A. C.; SÓ, L. L. S. Gasto público, descentralización y política de desarrollo rural: experiencias municipales en Brasil. Estudio de caso. In: BAQUERO, F. S.; ROCHA, J. S.; ORTEGA, J. (Orgs.). Políticas públicas y desarrollo rural en América Latina y el Caribe: el papel del gasto público. Santiago do Chile: Organizaciones de las Naciones Unidas para la Agricultura y Alimentación - FAO, v. 1, 2006.

RIBEIRO, E. M. As invenções de migrantes. Travessia: Revista do Migrante, ano 6, n. 17, set./dez. 1993. RIBEIRO, E. M.; GALIZONI, F. M.; ASSIS, T. P. Os caminhos de São Paulo. Revista Brasileira de Estudos de População, v. 21, n. 2, jul./dez. 2004.

RIBEIRO, E. M.; ARAÚJO, D. P.; GALIZONI, F. M. Uma estimativa preliminar das receitas monetárias e não-monetárias de agricultores familiares do Vale do Jequitinhonha. In: ORTEGA, A. C.; ALMEIDA FILHO, N. (Orgs.). Desenvolvimento territorial, segurança alimentar e economia solidária. São Paulo: Alínea, 2007.

RIBEIRO, E. M.; GALIZONI, F. M. Sistemas agrários, recursos naturais e migrações no Alto Jequitinhonha, Minas Gerais. In: TORRES, H.; COSTA, H. (Orgs.). População e meio ambiente: debates e desafios. São Paulo: Senac-SP, 2000.

RIOS NETO, E.; VIEIRA, P. M. R. D. Mulheres de migrantes sazonais no Vale do Jequitinhonha. In: NABUCO, M. R. (Org.). Contradições do desenvolvimento agrícola de Minas Gerais: uma perspectiva regional. Belo Horizonte: Cedeplar/UFMG, 1990. 
SACCO DOS ANJOS, F.; CALDAS, N. V. O futuro ameaçado: o mundo rural face os desafios da masculinização, envelhecimento e desagrarização. Ensaios (FEE), v. 26, n. 1, jun. 2005.

Pluriatividade e sucessão hereditária na agricultura familiar. In: SCHNEIDER, S. (Org.). A diversidade da agricultura familiar. Porto Alegre: UFRGS, v. 1, 2006.

SANT’ANA, A. L.; COSTA, V. M. H. M. Produtores familiares e estratégias ligadas à terra. RER, v. 42, n. 4, out./dez. 2004.

SEYFERTH, G. Herança e estrutura familiar camponesa. Boletim do Museu Nacional, Rio de Janeiro, n. 52, maio de 1985.

SILVESTRO, M. L.; ABRAMOVAY, R.; MELLO, M. A. de; DORIGON, C.; BALDISSERA, I. T. Os impasses sociais da sucessão hereditária na agricultura familiar. Florianópolis: Epagri; Brasília, DF: Nead/Ministério do Desenvolvimento Agrário, 2001. Disponível em: 〈http://www.nead.org.br〉. Acesso em: 23 fev. 2007.

WOLF, E. R. Sociedades camponesas. 2. ed. rev. Rio de Janeiro: Zahar, 1976.

WOORTMANN, E. F. Herdeiros, parentes e compadres. São Paulo: Hucitec, 1994.

WOORTMANN, E. F.; WOORTMANN, K. O trabalho da terra. Brasília, DF: UnB, 1997.

WOORTMANN, K. “Com parente não se neguceia”: o campesinato como ordem moral. Ciência Hoje, v. 5, n. 28, jan./fev. 1987.

Migração, família e campesinato. Revista Brasileira de Estudos de População, v. 7, n. 1, jan./jun. 1990.

\section{Autores}

Kenia Fabiana Cota Mendonça é contabilista e mestre em Administração. Professora do Departamento de Ciências Contábeis da Univesidade Federal dos Vales do Jequitinhonha e Mucuri.

Eduardo Magalhães Ribeiro é economista e doutor em História. Pesquisador do CNPq e do Programa Pesquisador Mineiro da Fapemig e professor do Instituto de Ciências Agrárias da Universidade Federal de Minas Gerais - UFMG.

Flávia Maria Galizoni é antropóloga e doutora em Ciências Sociais. Professora do Instituto de Ciências Agrárias da Universidade Federal de Minas Gerais - UFMG.

Hélder Anjos Augusto é administrador e doutor em Demografia. Professor do Instituto de Ciências Agrárias da Universidade Federal de Minas Gerais - UFMG.

\section{Abstract \\ Training, succession and migration: histories of two generations of farmers in the Upper Jequitinhonha River Area, Minas Gerais}

Family farming is a key sector for supplying food, generating employment and maintaining traditional cultures in the Brazilian countryside. According to several authors, the reproduction of family farming is threatened by the emigration of young people, due to current changes in urban and rural settings. This paper investigates this situation in two municipalities in the upper Jequitinhonha Valley - a region strongly characterized by the presence of family farming - through an analysis of the history of two generations of farmers. The results indicate changes in inheritance patterns, educational levels and the traditional dynamics of the empowerment of youth, all of which in turn influence the life histories and the integration of migrants into the labor market. The article concludes that, in comparison with previous 
generations, fewer young people stay in the countryside, although this does not put the reproduction of family units in risk, because many people do stay in rural areas and take over properties at more advanced ages and higher educational levels than did previous generations.

Keywords: Family farming. Succession. Rural youth. Jequitinhonha Valley.

\section{Resumen}

Formación, sucesión y migración: trayectorias de dos generaciones de agricultores del Alto Jequitinhonha, Minas Gerais

La agricultura familiar es un sector clave para el abastecimiento alimentario, la generación de ocupaciones y el mantenimiento de las culturas propias del medio rural brasileño. De acuerdo con varios autores, la continuidad de este sector de agricultores ha sido amenazada por la gran emigración de jóvenes en función de transformaciones ocurridas en los medios urbano y rural. En este artículo se analiza esta situación en dos municipios del Alto Jequitinhonha, Minas Gerais - región fuertemente marcada por la presencia de la agricultura familiar -, investigando las trayectorias emigratorias de dos generaciones de agricultores. Los resultados indican cambios en el estándar sucesorio, en los niveles de escolaridad y en la dinámica tradicional de capacitación de los jóvenes, lo que influye en los recorridos y en la inserción de los migrantes en el mercado laboral. El artículo concluye que, en comparación con la generación anterior, un menor número de jóvenes permanece en el medio rural. Pero esto no pone en riesgo la reproducción de la unidad familiar, ya que siguen existiendo sucesores, aunque estos tiendan a asumir la unidad productiva con más edad y escolaridad que la generación anterior.

Palabras clave: Agricultura familiar. Sucesión. Juventud rural. Vale do Jequitinhonha.

Recebido para publicação em 22/05/2011

Aceito para publicação em 31/12/2011 
